\title{
AMPA, not NMDA, activates RhoA GTPases and subsequetly phosphorylates moesin
}

\author{
Su-Jin Kim ${ }^{1}$, Songhee Jeon ${ }^{1}$, Eun-Young Shin ${ }^{2}$ \\ Eung-Gook Kim ${ }^{2}$, Joobae Park ${ }^{1}$ and \\ Chang-Dae $\mathrm{Bae}^{1,3}$ \\ ${ }^{1}$ Department of Molecular Cell Biology \\ Sungkyunkwan Univresity School of Medicine \\ Suwon 440-746, Korea \\ ${ }^{2}$ Department of Biochemistry \\ College of Medicine Chungbuk National University \\ Cheongju 361-763, Korea \\ ${ }^{3}$ Corresponding author: Tel, 82-31-299-6133; \\ Fax, 82-31-299-6149; E-mail, cdbae@med.skku.ac.kr
}

Accepted 27 January 2004

Abbreviations: AMPA, a-Amino-3-hydroxy-5-methyl-4-isoxazolepropionic acid; ERM, ezrin-radixin-moesin; NMDA, N-methyl DAspartate; ROK, Rho kinase

\begin{abstract}
Glutamate induced rapid phosphorylation of moesin, one of ERM family proteins involved in the ligation of membrane to actin cytoskeleton, in rat hippocampal cells (JBC, 277:16576-16584, 2002). However, the identity of glutamate receptor has not been explored. Here we show that a-amino3-hydroxy-5-methyl-4-isoxazolepropionic acid (AMPA) receptor is responsible for glutamate-induced RhoA activation and phosphorylation of moesin. Glutamate induced phosphorylation at Thr-558 of moesin was still detectible upon chelation of $\mathrm{Ca}^{2+}$, suggesting involvement of AMPA receptor instead of $\mathrm{N}$-methyl D-Aspartate (NMDA) receptor in this phosphorylation of moesin. AMPA but not NMDAinduced moesin phosphorylation was independent of $\mathrm{Ca}^{2+}$. Both AMPA and NMDA but not Kainate induced moesin phosphorylation at similar levels. However, the kinetics of phosphorylation varied greatly between AMPA and NMDA where AMPA treatment rapidly increased phosphomoesin, which reached a maximum at $10 \mathrm{~min}$ after treatment and returned to a basal level at $30 \mathrm{~min}$. In contrast, NMDA-induced phosphorylation of moesin reached a maximum at $30 \mathrm{~min}$ after treatment and was remained at higher levels at $60 \mathrm{~min}$. A possible involvement of RhoA and its
\end{abstract}

downstream effector, Rho kinase in the AMPA receptor-triggered phosphorylation of moesin was also explored. The kinetics for the glutamate- in duced membrane translocation of RhoA was similar to that of moesin phosphorylation induced by AMPA. Moreover, Y-27632, a specific Rho kinase inhibitor, completely blocked AMPA-induced moesin phosphorylation but had no effect on NMDA-induced moesin phosphorylation. These results sug. gest that glutamate-induced phosphorylation of moesin may be mediated through the AMPA receptor/RhoA/Rho kinase pathway.

Keywords: AMPA; Moesin; NMDA; Rho GTPase; ROK; phsophorylation

\section{Introduction}

Moesin is one of ERM family proteins and is expressed ubiquitously. Major proposed function of moesin is ligation of membrane to actin cytoskeleton (Bretscher et al., 2002). When phosphorylated at Thr-558 of moesin, intramolecular association between $\mathrm{N}$ terminus and C-terminus of moesin is disrupted. Subsequently $\mathrm{N}$-terminal FERM domain of moesin is exposed, which in turn links C-terminal tail to membrane proteins such as I-CAM and actin cytoskeleton. ROK and PKC are reported to phosphorylate moesin. Previously, we reported phosphorylation of moesin by electroconvulsive shock and suggested glutamate-mediated RhoA-ROK activation might be an underlying mechanism (Jeon et al., 2002).

Involvement of Rho GTPase in glutamate receptor signaling has also been reported from other laboratories (Husi and Grant, 2001). Citron, a Rho GTPase target has been reproted to interact with PSD-95 in postssynaptic density underlying NMDA receptor in thalamus (Furuyashiki, et al., 1999; Zhang et al., 1999). Glutamate receptor and Rho GTPase have been proposed to be essential to dendrite growth in Xenopus (Sin et al., 2002). A Rho-GAP, RICS (Okabe et al., 2003) as well as several Rac/Cdc42-specific Rho-GEF, such as Kalirin-7 (Penzes et al., 2001), dPix (Parnas et al., 2002) and bPIX (Park et al., 2003), have been reported to play a role in dendrite remodeling. These reports are focusing on the involvement of Rho GTPases in dendritic morphogenesis through NMDA receptor and suggest that Rac and 
Cdc42 activities enhance dendritic remodeling while RhoA activity inhibits (Wong et al., 2000; Li et al., 2002; Sin et al., 2002). Thus, RhoA would be inactive in NMDA receptor-mediated dendrite remodeling. However, our previous results indicated that glutamate stimulation led to activation of RhoA-ROK pathway, in hippocampal progenitor cells, H19-7/IGF-IR cells. One possible explanation about this discrepancy might be that RhoA is activated through glutamate receptor subfamily other than NMDA receptor. Thus so far no evidence on direct involvement of RhoA in AMPA or kinate signaling has been reported. In this study, we sought to determine which ionotropic glutamate receptor subfamily could activate RhoA-ROK pathway and subsequently phosphorylate moesin.

\section{Materials and Methods}

\section{Materials}

H19-7/IGF-IR cells were obtained from the American Type Culture Collection (Manassas, VA). Mouse monoclonal RhoA antibody was obtained from Santa Cruz Biotechnology (Santa Cruz, CA). Y27632 was purchased from Tocris (Ellisville, MO).

\section{Cell culture}

H19-7/IGF-IR cells were maintained in DMEM containing $10 \%$ fetal bovine serum, $200 \mathrm{mg} / \mathrm{ml} \mathrm{G} 418$, and $1 \mathrm{mg} / \mathrm{ml}$ puromycin at $34^{\circ} \mathrm{C}$ under $5 \% \mathrm{CO}_{2} . \mathrm{H} 19-7 /$ IGF-IR cells were seeded at $1 \times 10^{6}$ in a $60 \mathrm{~mm}$ dish. For AMPA or Kainate treatment, the cells were cultured in serum-free DMEM for $20 \mathrm{~h}$ and incubated with Kreb's buffer $(126 \mathrm{mM} \mathrm{NaCl}, 3.5 \mathrm{mM} \mathrm{KCl}, 1.2$ $\mathrm{mM} \mathrm{NaH}{ }_{2} \mathrm{PO}_{4}, 1.3 \mathrm{mM} \mathrm{MgCl}, 2 \mathrm{mM} \mathrm{CaCl}, 10 \mathrm{mM}$ glucose, $\left.25 \mathrm{mM} \mathrm{NaHCO}_{3}, \mathrm{pH} 7.4\right)$. And then the cells were stimulated with $100 \mathrm{mM}$ glutamate, AMPA (a-amino-3-hydroxy-5-methyl-4-isoxazolepropionic acid) or Kainate for various periods $(2,5,10,30$, and $60 \mathrm{~min})$. And the cells were incubated with $\mathrm{Mg}^{2+}$ free Kreb's buffer to treat the cells with NMDA or glutamate. Because NMDA receptors are blocked with $\mathrm{Mg}^{2+}$ ion. To chelate $\mathrm{Ca}^{2+}$ ion, the cells were incubated with Kreb's buffer containing $5 \mathrm{mM}$ EGTA for $90 \mathrm{~min}$ before the glutamate, AMPA, or NMDA treatments. To examine the involvement of Rho kinase in glutamateinduced moesin phosphorylation, we used a Rho kinase inhibitor, $Y-27632$. Before the glutamate treatment, H19-7/IGF-IR cells were incubated with Kreb's buffer containing $30 \mathrm{mM} \mathrm{Y}-27632$ for $1 \mathrm{~h}$. The cells were rinsed out with cold phosphate buffered saline and then lysed in $1 \times$ Laemmli buffer. The samples were boiled at $100^{\circ} \mathrm{C}$ for $10 \mathrm{~min}$.

\section{Subcellular fractionation}

H19-7/IGF-IR cells were seeded at $1.25 \times 10^{6}$ in 100 $\mathrm{mm}$ dishes. For glutamate treatment, the cells were cultured in serum-free DMEM for $20 \mathrm{~h}$ and incubated with Kreb's buffer. And then the cells were stimulated with or without $100 \mathrm{mM}$ glutamate for various period $(2,5,10,30,60 \mathrm{~min})$. Then the cells were rinsed with cold phosphate-buffered saline and lysed in detergent-free buffer $(50 \mathrm{mM}$ TrisCl, $150 \mathrm{mM} \mathrm{NaCl}$, $5 \mathrm{mM} \mathrm{MgCl}$, $1 \mathrm{mM} \mathrm{NaVO}_{3}, 10 \mathrm{mg} / \mathrm{ml}$ Leupeptin, 10 $\mathrm{mg} / \mathrm{ml}$ aprotinin, $1 \mathrm{mM}$ PMSF, $\mathrm{pH} 8.0$ ) by passing 15 times through a 25 gauge needle. The lysed cells were centrifuged at $1,000 \mathrm{~g}$ for $10 \mathrm{~min}$. The supernatants were centrifuged at $100,000 \mathrm{~g}$ for $1 \mathrm{~h}$. The supernatants were used as cytosol, and the pellets as crude membrane. The supernatants were added with $5 \times$ Laemmli buffer and the pellets were melted in $1 \times$ Laemmli buffer. Then the samples were boiled at $100^{\circ} \mathrm{C}$ for $10 \mathrm{~min}$.

\section{Western blots}

To analyze the amount of phosphorylated moesin, the samples were separated by SDS-polyacrylamide gel electrophoresis $(10 \%)$ and then electrophoretically transferred from gels onto nitrocellulose membranes. To analyze the amount of translocated RhoA, we used $15 \%$ polyacrylamide gels and polyvinylidene fluoride membrane. Blots were blocked with $5 \%$ nonfat dry milk in TBS containing $0.05 \%$ Tween-20 for $1 \mathrm{~h}$, incubated with 1:3,000 rabbit antisera in $5 \%$ milk followed by 1:5,000 peroxidase-conjugated donkey antirabbit IgG in $5 \%$ milk or incubated with $1: 5,000$ RhoA antibody in $5 \%$ BSA followed by $1: 5,000$ peroxidaseconjugated goat anti-mouse lgG in $5 \%$ milk. Blots were developed using enhanced chemiluminescence $(E C L)$.

\section{Results and Discussion}

Phsphorylation of moesin at Thr-558 in H19-7/IGF-IR cells after glutamate, AMPA, NMDA, and Kainate treatments

As shown in Figure $1 A$ and $B$, glutamate stimulation induced rapid phosphorylation of moesin at Thr-558. Glutamate-induced moesin phosphorylation reached a peak at $10 \mathrm{~min}$ after stimulation and lasted up to 60 min. Glutamate is known to mediate its signal through 3 ionotropic subtypes and metabotropic subtype. In order to explore which glutamate receptor subtype mediates moesin phosphorylation, 3 ionotropic glutamate receptor agonists, NMDA, AMPA and Kinate were tested (Figure 1C, D, E). With treatment of AMPA, amount of phospho-moesin was rapidly increased, but returned to a pre-stimulated basal level after $30 \mathrm{~min}$ 
A

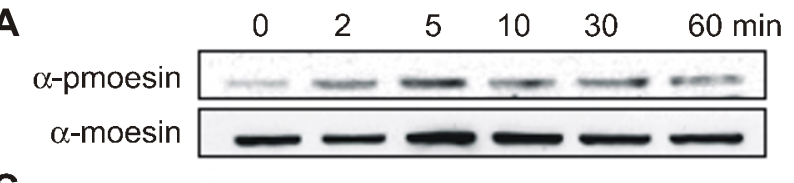

C

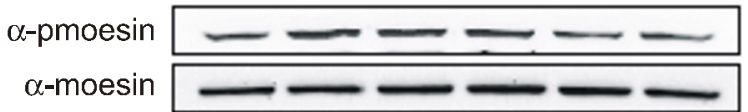

D

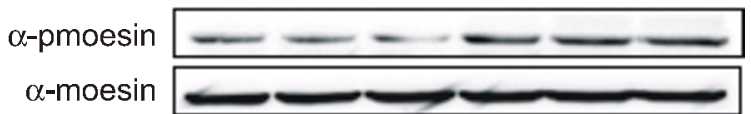

E

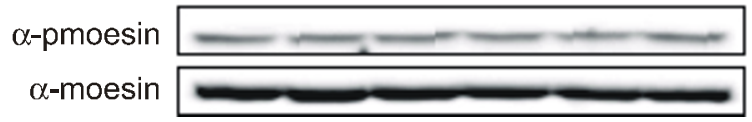

B

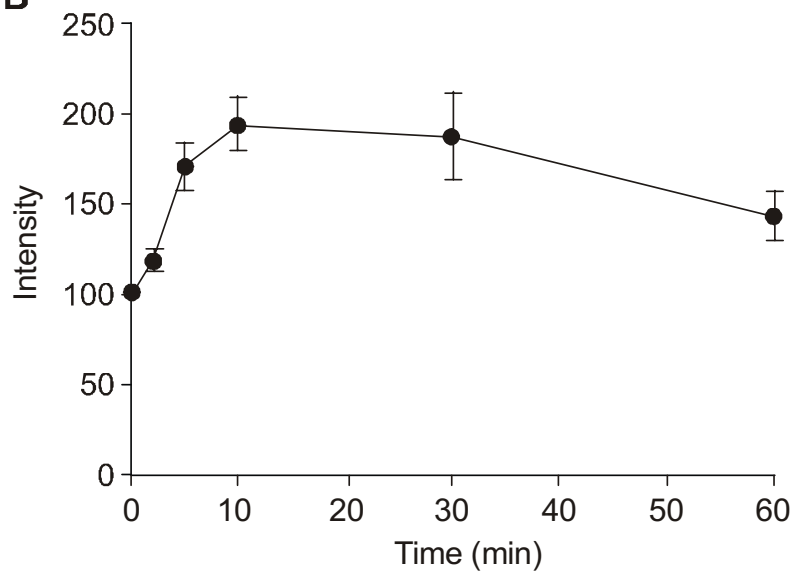

Figure 1. Phosphorylation of moesin upon stimulation with glutamate and glutamate receptor agonists in H19-7/IGF cells. (A) Phosphorylation of moesin was detected at 2 min after glutamate stimulation and lasted up to $60 \mathrm{~min}$. (B) Intensities of phosphomoesin bands were plotted over time after normalized against the intensity of corresponding total moesin band. (C-E) Serum starved H19-7/IGF-IR cells were stimulated with $\operatorname{AMPA}(C), \operatorname{NMDA}(D)$ or Kinate $(E)$.

(Figure $1 \mathrm{C}$ ). Since NMDA receptors are blocked in the presence of $\mathrm{Mg}^{2+}$ ion, H19-7/IGF-IR cells were incubated with $\mathrm{Mg}^{2+}$-free Kreb's buffer and then treated with NMDA. Phosphorylation of moesin was also induced by NMDA but the time course of phosphorylation was totally different from that induced by AMPA. NMDA-induced phophorylation of moesin was observed at $10 \mathrm{~min}$ and last over $60 \mathrm{~min}$ much longer than AMPA-induced phosphorylation (Figure 1D). The amplitude of phosphorylation of moesin was quite comparable, about $50 \%$ over basal level on between AMPA and NMDA stimulation. Kinate stimulation had no effect on phosphorylation of moesin (Figure 1E) although kinate-induced seizures could activate intracellular signaling pathway in hippocampus (Lee et al., 2002). From the results of the moesin phosphorylation pattern on glutamate stimulation appears to be the summation of phosphorylation of moesin on both AMPA and NMDA stimuli. Taken together, both AMPA and NMDA are found capable of phosphorylating moesin in H19-7/IGFR cells but in a different time course.

\section{Effect of $\mathrm{Ca}^{2+}$ on glutamate-induced phosphorylation of moesin}

Among the three major subtypes of glutamate receptors, NMDA receptor would likely be the major participants because of its possible relation with short-term memory. Major ion required for NMDA receptor function is suggested to be $\mathrm{Ca}^{2+}$ ion where $\mathrm{Ca}^{2+}$-mediated signaling cascade is reported to be crucial to NMDAmediated long-term potentiation. Thus, the effect of $\mathrm{Ca}^{2+}$ ion on the phorphorylation of moesin upon glutamate stimulation was examined. As shown in Figure
A

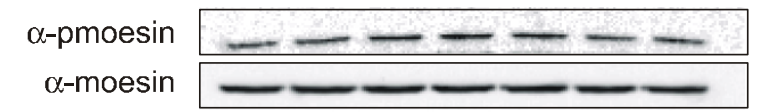

B

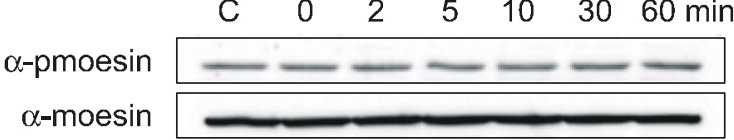

C

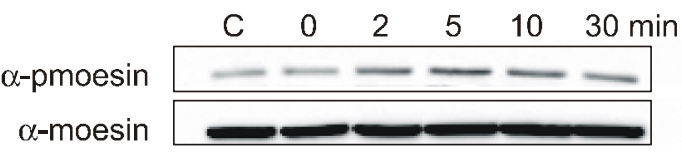

Figure 2. Effect of $\mathrm{Ca}^{2+}$ on phosphorylation of moesin by gluR agonists. Serum-starved H19-7/IGF-IR cells were pre-incubated with EGTA. EGTA-treated cells were stimulated with glutamate (A), NMDA (B) or AMPA (C).

$2 \mathrm{~A}$, phosphorylation of moesin returned to basal levels at $30 \mathrm{~min}$ after glutamate stimulation in the absence of $\mathrm{Ca}^{2+}$ ion, much faster than in the presence of $\mathrm{Ca}^{2+}$ ion, which indicated that early phase phosphorylation of moesin was independent of $\mathrm{Ca}^{2+}$ ion while late phase phosphorylation of moesin was dependent of $\mathrm{Ca}^{2+}$ ion. Based on such observation, the glutamate stimulation of moesin phosphorylation may involve both AMPA receptor at early phase and NMDA receptor at late phase. To confirm this idea, the effect of calcium chelation on phosphorylation of moesin was tested on both AMPA and NMDA receptors. As shown in Figure $2 \mathrm{C}$, pretreatment of cells with EGTA for 90 min completely blocked NMDAinduced phosphorylation of moesin, suggesting that 
phosphorylation of moesin was totally dependent on $\mathrm{Ca}^{2+}$ influx through NMDA receptor. However, AMPA could still phosphorylate moesin in the absence of $\mathrm{Ca}^{2+}$ ion in medium even though AMPA receptor is known to allow passage of $\mathrm{Na}^{+}, \mathrm{K}^{+}$, and $\mathrm{Ca}^{2+}$ (Figure 2C). Metal ion requirement experiments support that moesin phosphorylation on glutamate stimulation was likely the summation effect of both AMPA and NMDA. NMDA phosphorylated moesin in a delayed, $\mathrm{Ca}^{2+}$ dependent manner, suggesting that NMDA-induced moesin phosphorylation might occur in the subcellular location other than postsynaptic density and through a $\mathrm{Ca}^{2+}$-dependent downstream pathway. However, rapid and transient nature of AMPA-induced moesin phosphorylation suggests that it might occur in postsynaptic density and through direct downstream pathway to AMPA receptor.

\section{AMPA, not NMDA, phosphorylated moesin through RhoA-ROK pathway}

Since glutamate-induced moesin phosphorylation was inhibited by a ROK inhibitor (Jeon et al., 2002), it would be a choice experiment to define major path for respective receptors, either AMPA or NMDA or both to be linked with RhoA small GTPase in the glutamate-induced moesin phosphorylation. Figure $3 \mathrm{~A}$ shows the glutamate induced membrane translocation of RhoA. The amount of membrane-translocated RhoA was increased at 2 min after AMPA stimulation and returned to basal levels at $30 \mathrm{~min}$. The kinetics of RhoA translocation exactly matched that of moesin phosphorylation by AMPA, suggesting that glutamateinduced membrane translocation of RhoA might be through AMPA receptor and AMPA-induced moesin phosphorylation might be conducted by ROK. When ROK was blocked with Y27632, a ROK inhibitor, AMPAinduced moesin phosphorylation was totally blocked. However, NMDA-induced mosesin phosphorylation was not effected at all (Figure 3B, C). Follow up experiment of Moesin phosphorylation for longer time period showed that NMDA-induced moesin phosphorylation was terminated at $90 \mathrm{~min}$ after stimulation.

These observations indicated that AMPA, not NMDA, induced activation of RhoA-ROK pathway and it was ROK that phosphorylated moesin. Involvement of RhoA in AMPA signaling was not totally unexpected since Rac and Cdc42 GTPase have already been proposed to be involved in NMDA signaling as described in introduction. Our result that NMDA didn't activate RhoA also matched to the previous reports in which Rac and Cdc42 GTPase, not RhoA, might be involved in NMDA-induced dendrite remodeling (Penz et al., 2001; Park et al., 2003). Possible involvement of RhoA GTPase signaling has been proposed in metabotropic glutamate receptor signaling
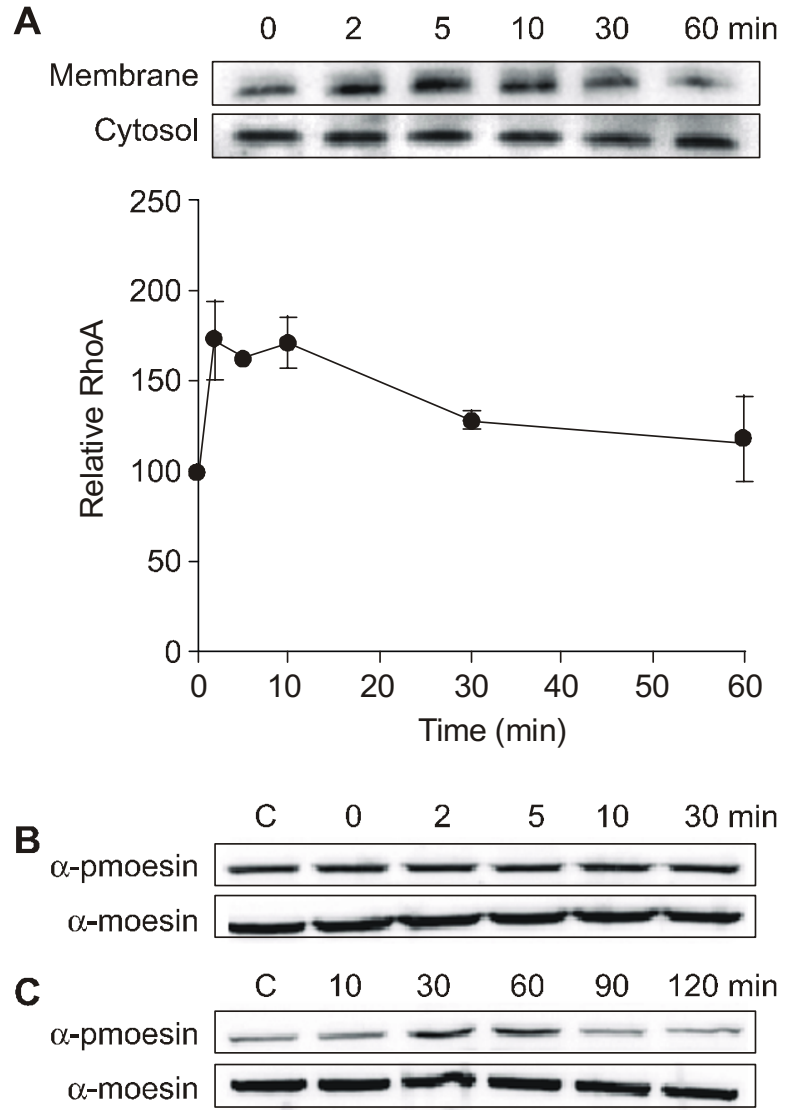

Figure 3. Membrane translocation of RhoA by glutamate and effect of Y27632 on the phosphorylation of moesin at Thr-558. A. Serumstarved H19-7/IGF-IR cells were stimulated with glutamate. Whole cell lysates were fractionated into membrane and cytosol fractions. The amount of RhoA in each fraction was determined by Western blot (top). The intensities of RhoA band in membrane fractions were plotted over time (bottom). B and C. Serum-starved H19-7/IGF-IR cells pre- incubated with Rho kinase inhibitor, Y-27632, were stimulated with AMPA (B) or NMDA (C). Lysates were then processed as described above.

(Kanumilli et al., 2001) and in glutamate signalling in hippocampal cell line, H19-7 cells (Jeon et al., 2002).

Since almost all the reports suggested involvement of Rac and Cdc42 GTPases in glutamate signaling instead of RhoA GTPase and reciprocal action between Rac and RhoA in dendrite remodeling, one can doubt what is the possible role of activation of RhoA and subsequent phosphorylation of moesin by AMPA. One possible hint might come from the report that C3 exotoxin, an inhibitor of RhoA, inhibited rundown of NMDA receptor channels (Nreberg et al., 1999), in which authors suggested that ligation of NMDA receptor and actin cytoskeleton by RhoA might be crucial for regulation of NMDA receptor activity but failed to show actual activation of RhoA. In this context, our result might be a missing puzzle fragment, that is, AMPA activated RhoA leading to polymeriz- 
ation of actin cytoskeleton and also phosphorylate moesin by RhoA-ROK leading to ligation of AMPA or NMDA receptor to underlying actin cytoskeleton since phopshorylation of moesin has been reported to be crucial in memebrane-cytoskeleton ligation (Bretscher et al., 2002).

Recent study that a myosin/moesin phosphatase inhibitor, CPI-17 is crucial for cerebellar long-term depression through AMPA receptor (Eto et al., 2002) might be another clue for the role of moesin in AMPA receptor signaling. In this study, silencing $\mathrm{CPI}-17$ by si-RNA blocked long-term depression (LTD) induction although significance of moesin phosphorylation in LTD is not directly proved. So it would be interesting to investigate what effect AMPA-activated RhoA and moesin might have on NMDA receptor activity since transient depolarization of membrane induced by AMPA is known to be crucial in NMDA receptor opening.

In conclusion, AMPA stimulation activated RhoA and in turn ROK followed by phosphorylation of moesin, while NMDA stimulation also phosphorylated moesin but in a different pathway other than RhoA-ROK pathway.

\section{Acknowledgment}

This work was supported by Korea Research Foundation Grant \#2000-042-F00010.

\section{References}

Bretscher A, Edwards K, Fehon RG. ERM proteins and merlin:integrations at the cell cortex. Nat Rev Mol Cell Biol 2002;3:586-99

Eto $M$, Bock R, Brautigan DL, Linden DJ. Cerebellar longterm synaptic depression requires PKC-mediated activation of CPI-17, a myosin/moesin phosphatase inhibitor. Neuron 2002;36:1145-58

Furuyashiki T, Fujisawa K, Fujita A, Madaule P, Uchino S, Mishina $M$, Bito $H$, Narumiya $S$. Citron, a Rho-Target, interacts with PSD-95/SAP-90 at glutamatergic synapeses in the thalamus. J Neuroscience 1999;19:109-18

Husi H, Grant SGN. Proteomics of the nervous system. Trends in Neuroscience 2001;24:259-66

Jeon SH, Kim SH, Park JB, Suh PG, Kim YS, Bae CD, Park JB. RhoA and Rho Kinase-dependent phosphorylation of moesin at Thr-558 in hippocampal neuronal cells by glutamate. JBC 2002;277:16576-84
Kanumilli S, Toms NJ, Venkateswarlu K, Mellor H, Roberts PJ. Functional coupling of rat metabotropic glutamate la receptors to phospholipase $\mathrm{D}$ in $\mathrm{CHO}$ cells: involvement of extracellular, protein kinase $C$, tyrosine kinase and Rho-A. Neuropharmacology 2002;42:1-8

Lee MY, Kim SY, Choi JS, Choi YS, Jeon MH, Lee JH, Kim IK, Lee JH. Induction of Bis, a Bcl-2-binding protein, in reactive astrocytes of the rat hippocampus following kainic acid-induced seizure. Exp Mol Med 2002;34:167-71

Li Z, Aizenman CD, Cline HT. Regulation of Rho GTPases by crosstalk and neuronal activity in vivo. Neuron 2002;33: 741-50

Liu H, Cunto FD, Imarisio S, Reid LM. Citron kinase is a cell cycle-dependent, nuclear protein required for $\mathrm{G} 2 / \mathrm{M}$ transition of hepatocytes. JBC 2003;278:2541-8

Nöreberg W, Hofmann F, Illes P, Aktories K, Meyer DK. Rundown of somatodendritic $N$-methyl-D-aspartate (NMDA) receptor channels in rat hippocampal neurones: evidence for a role of the small GTPase RhoA. Br J Pharm 1999;127: 1060-3

Okabe T, Nakamura T, Nishimura YN, Kohu K, Ohwada S, Morishita Y, Akiyama T. RICS, a novel GTPase-activating protein for Cdc42 and Rac1, is involved in the b-catenin$\mathrm{N}$-cadherin and N-Methyl-D-aspartate receptor signaling. JBC 2003;278:9920-7

Park EH, Na MS, Choi JH, Kim SH, Lee JR, Yoon JY, Park DG, Sheng MG, Kim EJ. The shank family of postsynaptic density proteins interacts with and promotes synaptic accumulation of the bPIX guanine nucleotide exchange factor for Rac1 and Cdc42. JBC 2003;278:19220-9

Parnas D, Haghighi AP, Fetter RD, Kim SW, Goodman CS. Regulation of postsynaptic structure and protein localization by the Rho-Type guanine nucleotide exchange factor dPix. Neuron 2001;32:415-24

Penzes $P$, Johnson RC, Sattler R, Zhang $X$, Huganir RL, Kambampati V, Mains RE, Eipper BA. The neuronal Rho- GEF Kalirin-7 interacts with PDZ domain-containing proteins and regulates dendritic morphogenesis. Neuron 2001;29:229-42

Sin WC, Haas K, Ruthazer ES, Cline HT. Dendrite growth increased by visual activity requires NMDA receptor and Rho GTPases. Nature 2002;419:475-80

Wong WT, Faulkner-Jones BE, Sanes JR, Wong ROL. Rapid dendritic remodeling in the developing retina: dependence on neurotransmission and reciprocal regulation by Rac and Rho. J. Neuroscience 2000;20:5024-36

Zhang W, Vazquez L, Apperson M, Kennedy MB. Citron Binds to PSD-95 at glutamatergic synapses on inhibitory neurons in the hippocampus. J. Neuroscience 1999;19:96-108 